\title{
Dysfunctional Uterine Bleeding: A Clinico-Pathological Study at A Tertiary Care Centre
}

\author{
Ramesh. B.H ${ }^{1 *}$ and Rajeshwari $\mathrm{K}^{2}$ \\ ${ }^{1}$ Department of Pathology, Raichur Institute of Medical Sciences, Raichur, Karnataka 584102, India \\ ${ }^{2}$ Department of Pathology, Gulburga Institute of Medical Sciences, Gulburga, Kalaburagi, Karnataka 585101,India
}

\begin{abstract}
Background: Dysfunctional uterine bleeding (DUB) is a form of abnormal uterine bleeding and it is one of the most common presenting complains in gynecology outpatient department in all age groups.

Aim and Objectives: The present study aimed to study the clinical features and various histological patterns of endometrium in DUB and correlating histopathology of endometrium with clinical presentation in clinically diagnosed cases of DUB.

Methods: Present study is a descriptive type of study conducted over 111 cases over a period of one year from June 2015 - June 2016 in the department of pathology at a tertiary care centre

Results: Majority of patients with DUB were in 3rd to 4th decade (40.35\%) and were multiparous (93.3\%). Of the 111 cases, $51.35 \%$ of cases showed histological features associated with DUB. Menorrhagia was the most frequent presenting complaint (56.14\%) followed by metrorrhagia in $14.04 \%$. Proliferative phase $(50.88 \%)$ was the most common endometrial pattern seen with DUB cases in age group from 21-50 years. Endometrial hyperplasia occurred between the age group of 30-50years.

Conclusion: Menorrhagia is the most common presenting complaint with proliferative phase endometrium. Age has definite influence on endometrial histology. Histopathology remains the gold standard method of diagnosis of DUB and its types and to exclude the local causes, so as to plan the accurate management in DUB patients.
\end{abstract}

Keywords: Dysfunctional Uterine Bleeding, Histopathology, Endometrium.

\section{Introduction}

The normal menstrual cycle consists of length of 21-35 days, the duration of blood flow is 2-7 days and the amount of blood loss is $20-80 \mathrm{ml}$. The deviation from this normal pattern is recognized as abnormal. ${ }^{[1]}$

Abnormal uterine bleeding (AUB) can be further classified into two broad groups first due to organic causes with pathology and the second is the dysfunctional uterine bleeding (DUB) where there is absence of organic disease of the genital tract or according to Novak et al. DUB can be described as AUB from the uterus unassociated with the tumour, inflammation or pregnancy ${ }^{[2,3]}$

DUB can be classified into primary, secondary and iatrogenic groups. ${ }^{[3]}$ Primary DUB is due to dysfunction in hypothalamo-pitutary-ovarian axis or dysfunction in the endometrium itself. Secondary DUB is due to endocrinopathies, haematological, vascular diseases and liver diseases. Iatrogenic DUB may occur due to drugs, exogenous harmone administration and intrauterine contraceptive devices. ${ }^{[4]}$

Abnormal uterine bleeding is one of the most common clinical problems in gynaecology ${ }^{[5]}$. The cause for the bleeding in women is related to hormonal disturbances, pregnancy complications, bleeding diathesis and more importantly local pathology including benign, malignant tumors and infection ${ }^{[6]}$. Dysfunctional uterine bleeding (DUB) is the term used to describe abnormal uterine bleeding not associated with organic lesions of uterus ${ }^{[7]}$.

In most cases, it is associated with anovulatory or oligoovulatory cycles, leading to a shoot in the estrogen levels, which are unopposed due to absence of progesteron ${ }^{[8]}$. During adolescence, it may be due to a failure of the hypothalamo-pituitary system to respond to the positive feedback of estrogen. In the perimenopausal years, the anovulatory bleeding may be due to the declining functional capacity of ovary or a careful screening for malignancy is imperative and should be treated promptly ${ }^{[9,10]}$.

Giving the importance of DUB in gynaecopathology, the present study was undertaken to study the endometrial patterns in clinically diagnosed DUB cases and to correlate the histopathological findings of endometrium with clinical behavior presented by the patient in DUB and also to know the prevalence of DUB cases at our tertiary care centre. 


\section{Materials and Methods}

Present study is a descriptive type of study conducted over 111 cases over a period of one year from June 2015- June 2016 in the department of pathology at a tertiary care centre.

Following inclusion and excusion criteria were adopted in our study -

Inclusion Criteria: 1.All patients who were diagnosed clinically as DUB cases. 2. None of these patients has a organic lesions detected either by clinically or ultrasonographycally.3. The clinical diagnosed DUB cases with only hysterectomy specimens were included in the present study.

Exclusion Criteria: 1. Adoloscent age group with clinical diagnosis of DUB. 2. Inadequate and improperly preserved specimens were excluded. 3. Hysterectomy specimens with incidental organic pathology diagnosed on gross were excluded.

Hysterectomy specimens received to the department of pathology were subjected to detailed gross examination and fixed in $10 \%$ buffered neutral formalin and processed. The sections of 3-4 microns were cut and stained with haematoxylin and eosin for histopathological diagnosis. A detailed clinical history, gynaecological examination and radiological findings were recorded. The clinical and histopathological findings were analyzed and following observations were made.

Statistical Analysis: The collected data was tabulated, analyzed and subjected for statistical analysis using SPSS 17.0. Results are presented as range for quantitative data and number and percentage for qualitative data.

\section{Results}

A total of 622 hysterectomy specimens were received to the deprtment of pathology out of which clinically diagnosed DUB cases with hysterectomy accounted for $17.85 \%$ (111 of cases) of the total specimens received. Among the clinical diagnosed DUB cases 51.35\% (54 cases) showed uteri without any organic pathology and $48.65 \%$ (54 cases) showed uteri with organic pathology as shown in (Graph1).
The common age group encountered in our study ranged between 21-70 years. DUB was most commonly observed in the age group of 31-40years accounting for $40.35 \%$ of the cases as shown in table1.

DUB was more commonly seen in multiparous (93.3\%) than in nulliparous women.The most common menstrual disorder in women presenting with DUB was menorrhagia in $56.15 \%$ of the cases followed by metrorrhagia in $14.05 \%$ of the cases, post menopausal bleeding in $8.77 \%$ of the cases, menometrorrhagia and polymenorrhagia in $7.01 \%$ of the cases as shown in table 2 .

Normally the duration of symptoms ranged from a minimum of four days to a maximum of seven years. In our study the most common duration of symtoms we encountered was one year in $42.11 \%$ of the cases ( 24 cases).

In the present study, we also observed that most of the patient with DUB were anemic with low haemoglobin< 10 grams $\%$ accounting for $89.47 \%$ of the cases( 51 cases).

Histopathological features:Out of total 57 cases of DUB without organic pathology, majority of the cases had anovulatory pattern of endometrium accounting for $84.21 \%$ of the cases. Ovulatory pattern of endometrium was detected in $15.79 \%$ of the cases.

Among the anovulatory endometrium most common histological pattern observed in our study is proliferative phase accounting for $50.88 \%$ of DUB cases (Figure 1) followed by simple endometrial hyperplasia accounting for $17.54 \%$ of the cases (Figure 2), complex hyperplasia in $10.53 \%$ of the cases, atrophic endometrium in $3.50 \%$ of the cases and complex hyperplasia with atypia in 1.765 of the cases as shown in table 3 . Ovulatory pattern of endometrium showed secretory phase in $15.79 \%$ of the cases (Figure 3 ).

Our study also noted the correlation of clinical symptoms with histological patterns of endometrium and found that menorrhagia was the most common type of clinical bleeding in patient with proliferative phase contributing to $50.88 \%$ of the cases ( 29 cases) followed by secretary phase accounting for $15.79 \%$ of the cases ( 9 cases) and in endometrial hyperplasia in $29.83 \%$ of the cases (17 cases).

Table 1: The age distribution of patients presenting with DUB.

\begin{tabular}{|c|c|c|c|}
\hline SI. No. & Age (in years) & No. of cases (\%) & Percentage (\%) \\
\hline 1. & $21-30$ & 08 & 45.09 \\
\hline 2. & $31-40$ & 23 & 36.35 \\
\hline 3. & $41-50$ & 21 & 07.01 \\
\hline 4. & $51-60$ & 04 & 01.90 \\
\hline 5. & $61-70$ & $\mathbf{5 7}$ & $\mathbf{1 0 0 . 0}$ \\
\hline
\end{tabular}


Table 2: The salient clinical features in DUB

\begin{tabular}{|c|l|c|c|}
\hline SI. No. & Symptoms & No. of cases & Percentage (\%) \\
\hline 1. & Menorrhagia & 32 & 56.15 \\
\hline 2. & Metrorrhagia & 08 & 14.05 \\
\hline 3. & Postmenopausal bleeding & 05 & 08.77 \\
\hline 4. & Menometrorrhagia & 04 & 07.01 \\
\hline 5. & Polymenorrhage & 04 & 07.01 \\
\hline 6. & Continuous bleeding & 01 & 01.75 \\
\hline 7. & Amenorrhoea followed by bleeding & 02 & 03.50 \\
\hline 8. & Dysmenorrhoea & 01 & $\mathbf{2}$ \\
\hline & Total & $\mathbf{5 7}$ & $\mathbf{1 0 0}$ \\
\hline
\end{tabular}

Table 3: The distribution of various histologic pattern of endometrium in DUB

\begin{tabular}{|c|l|c|c|}
\hline SI. No & Type of Endometrium & No. of cases & Percentage (\%) \\
\hline 1. & Proliferative Phase & 29 & 50.88 \\
\hline 2. & Secretory Phase & 09 & 15.79 \\
\hline 3. & Atrophic endometrium & 02 & 03.50 \\
\hline 4. & Simple endometrial hyperplasia & 10 & 17.54 \\
\hline 5. & Complex hyperplasia & 06 & 10.53 \\
\hline 6. & Complex hyperplasia with atypia & 01 & 01.76 \\
\hline & Total & 57 & 100.00 \\
\hline
\end{tabular}

Table 4: The age distribution of various endometrial lesions in DUB

\begin{tabular}{|c|c|c|c|c|c|c|c|}
\hline Age (yrs) & $\begin{array}{c}\text { Proliferative } \\
\text { Phase }\end{array}$ & $\begin{array}{l}\text { Secretary } \\
\text { Phase }\end{array}$ & $\begin{array}{l}\text { Atrophic } \\
\text { Phase }\end{array}$ & $\begin{array}{c}\text { Simple } \\
\text { Hyperplasia }\end{array}$ & $\begin{array}{c}\text { Complex } \\
\text { Hyperplasia }\end{array}$ & $\begin{array}{l}\text { Complex with } \\
\text { atypia }\end{array}$ & Tota \\
\hline $21-30$ & 05 & 1 & 0 & 1 & 1 & 0 & 8 \\
\hline $31-40$ & 12 & 5 & 0 & 3 & 2 & 1 & 23 \\
\hline $41-50$ & 12 & 3 & 0 & 4 & 2 & 0 & 21 \\
\hline $51-60$ & 0 & 0 & 2 & 1 & 1 & 0 & 4 \\
\hline $61-70$ & 0 & 0 & 0 & 1 & 0 & 0 & 1 \\
\hline Total & 29 & 9 & 2 & 10 & 6 & 1 & 57 \\
\hline
\end{tabular}

Table 5: The comparison of endometrial patterns in DUB cases without organic pathology

\begin{tabular}{|l|c|c|c|c|c|c|}
\hline Endometrial pattern & $\begin{array}{c}\text { Mehrotra et } \\
\text { al.(\%) }\end{array}$ & $\begin{array}{c}\text { Dass \& } \\
\text { Chugh (\%) }\end{array}$ & $\begin{array}{c}\text { Patel et } \\
\text { al.(\%) }\end{array}$ & $\begin{array}{c}\text { Purandhare\& } \\
\text { Jhalam(\%) }\end{array}$ & $\begin{array}{c}\text { Katuwal } \\
\text { study (\%) }\end{array}$ & $\begin{array}{c}\text { Present } \\
\text { study(\%) }\end{array}$ \\
\hline Proliferative phase & 62.5 & 41.5 & 63.3 & 66.3 & 48.6 & 50.88 \\
\hline Secretory phase & 5.3 & 22.5 & 7.6 & 20.6 & 35.3 & 15.79 \\
\hline Atrophic phase & 2.6 & 1.8 & - & 6.1 & 6.8 & 03.50 \\
\hline Endometrial hyperplasia & 19.4 & 30.6 & 29.1 & 7.0 & 2.7 & 29.83 \\
\hline Others & - & 3.6 & - & - & - & - \\
\hline
\end{tabular}




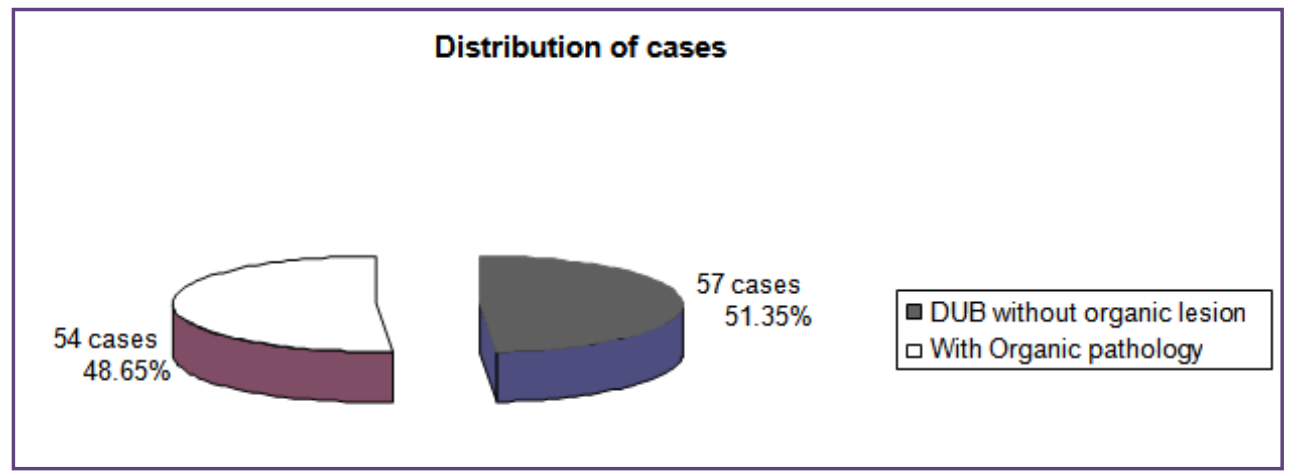

Graph 1: Distribution of cases clinically diagnosed as DUB

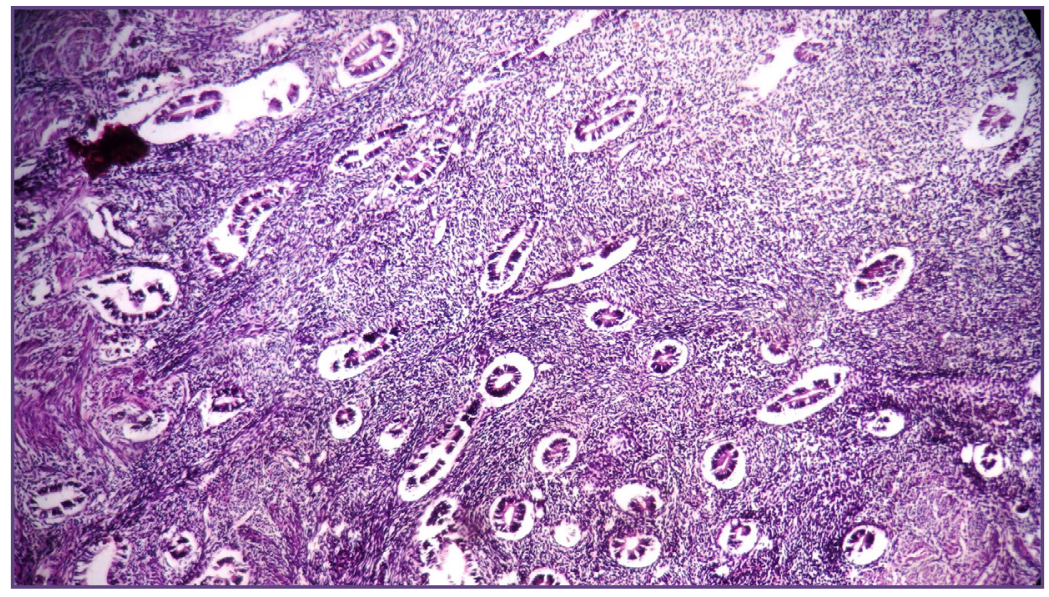

Fig. 1: Microphotograph of proliferative phase showing tubular glands with columnar cells surrounded by dense stroma with normal gland to stroma ratio.

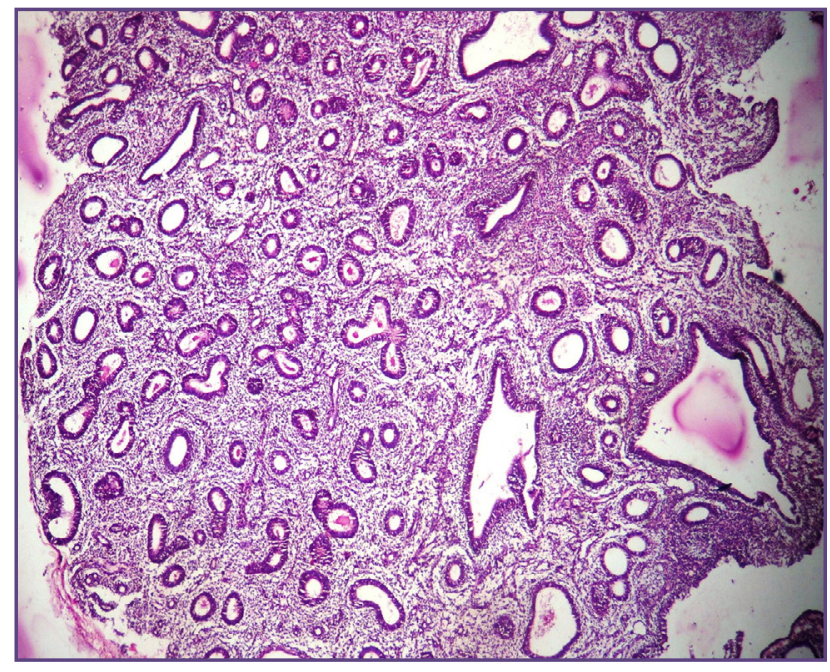

Fig. 2: Microphotograph of simple hyperplasia phase showing glands of varying sizes and shapes with cystic dilatation and increased gland to stroma ratio.

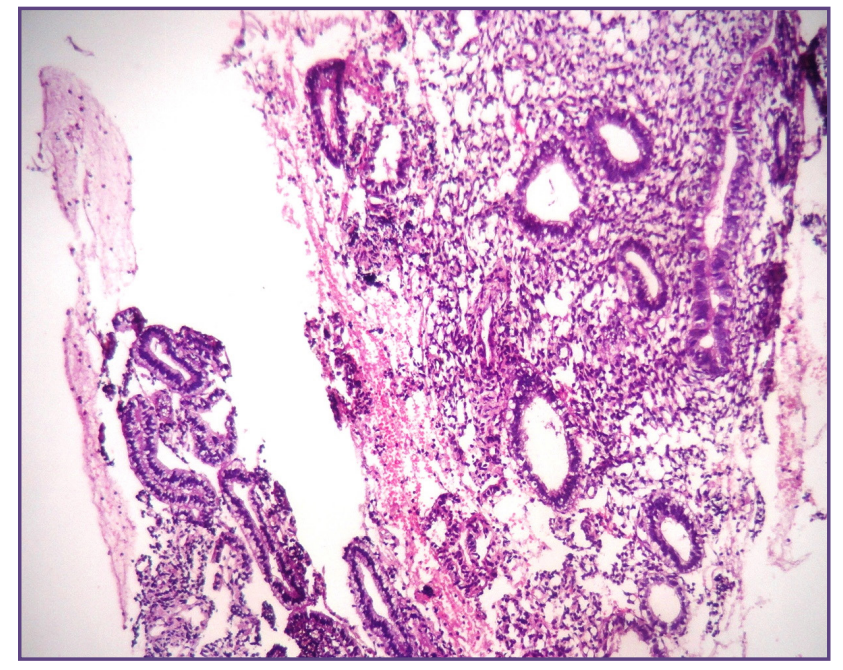

Fig. 3: Microphotograph of Secretary phase showing torturous glands with subnuclear vacuoles surrounded by oedematous stroma .Our study showed, proliferative phase was the most common histological pattern among adult reproductive age group and perimenapausal group accounting for $\mathbf{5 0 . 8 8 \%}$ of the DUB cases as shown in Table-4 


\section{Disscussion:}

Dysfunctional uterine bleeding is defined as abnormal uterine bleeding unrelated to anatomic lesions of the uterus. It is largely caused by aberrations in the hypothalamo-pituitary-ovarian hormonal axis ${ }^{[8]}$. DUB can occur in any type of endometrium both normal and abnormal ${ }^{[10]}$. Most of the cases occur during adolescence and perimenopausal years ${ }^{[7]}$.

The evaluation of AUB patient is achieved by identifying the DUB cases through various investigations like history, physical examination, laboratory diagnosis, ultrasonography and endometrial sampling.

The diagnosis of DUB remains as a diagnostic challenge to both Gynaecologists and Pathologists. Hence the present study was taken to highlight the DUB causes, its histopathological patterns of endometrium and its clinicopathological correlation in clinically diagnosed DUB patients.

Shergill et al and Patel et al reported the incidence of DUB among hysterectomies to be $26 \%$ and $49.65 \%$ respectively which is high compared to the present study of $17.85 \%$ ${ }^{[11,12]}$. Sucheta et al reported the commonest indication for hysterectomy was DUB in $33 \%$ of cases. The incidence is seen to be variable depending on the geographic regions [13].

Dass et al and Bhattacharji reported that majority of DUB cases occurred in 4th decade which correlated well with our study ${ }^{[14,15]}$. Whereas Pilli et al, Patel et al and Ghosh et al reported most cases in $4^{\text {th }} \& 5^{\text {th }}$ decades ${ }^{[10,12,16]}$.

The most common clinical symptoms in DUB cases were menorrhagia followed by metrorrhagia were observed by katuwal et al , Pilli et al, Patel et al, Mehrotra et al, Muzaffar et al and Bhosle et al studies. ${ }^{[4,10.12 .17,19,20]}$ Similar findings were observed in the present study and the results are in concordance with the above studies mentioned.

Among the duration of symtoms in DUB cases, Joshi et al observed that maximum number of cases had duration of 1-6 months (37\%) and $27.16 \%$ of patients had more than one year ${ }^{[18]}$ Whereas Ghosh et al observed the maximum number of cases had more than one year of symptoms in DUB cases ${ }^{[16]}$ and similar findings were seen in our study and the results correlated with Ghosh et al study.

Majority of the cases in the present study were multiparous $(93.33 \%)$ and correlated with the findings of Pilli et al and Joshi et al ${ }^{[10,18]}$. Patel et al reported $100 \%$ of patients were multiparous ${ }^{[12]}$. The incidence in the present study among nulli and uniparous was negligible as hysterectomy was performed only on patients who had completed their families except on one nulliparous patient due to the severity of her symptoms who was also in the perimenopausal age group.

Menorrhagia is one of the commonest causes of iron deficiency anemia in women of the reproductive age group. Comparison of the hemoglobin percentage shows a similar pattern of prevalence of varying degrees of anemia in DUB patients. The development of iron deficiency anemia initiates a compensatory mechanism which tends to reduce blood loss ${ }^{[16]}$.

The endometrial pattern in DUB cases (Table-5) without any organic pathology reveals a predominance of proliferative phase in most of the studies, suggesting that anovulation to be the main cause of DUB ${ }^{[9,12,14]}$.The incidence of proliferative phase in present study $(50.88 \%)$ is in concordance with Katuwal et al, Dass et al $(41.5 \%)$ and Mehrotra et al. $(62.5 \%)$ study $(48.6 \%)^{[4,14,17]}$. While Bhattacharji (19.6\%) and Joshi et al (31.7\%) reported lower incidence of proliferative phase ${ }^{[15,18]}$.

Similarly, the percentage incidence of secretary phase varied from $5.3 \%$ to $43.9 \%{ }^{[9,12,14,17]}$. The incidence of secretary phase (15.79\%) in present study is in concordance with Joshi et al study $(16.7 \%)^{[18]}$. The highest incidence of secretary phase was reported by Bhattacharji ( $43.9 \%$ ) and lowest incidence of $5.3 \%$ in Mehrotra et al. ${ }^{[15,117]}$ studies. The discrepancy may be due to the fact that unlike D\&C, which is performed in the premenstrual phase, performing hysterectomy is not bound by the phase of menstrual cycle.

The percentage of atrophic endometrium (3.50\%) in the present study has correlated with the study of Dass et al $(1.8 \%)^{[14]}$. Bhattacharji reported higher incidence of $7.3 \%$ [15]. Atrophy of the endometrium may be associated with large dilated venules situated superficially under a thin endometrium. These venules may rupture and are probably the commonest cause of postmenopausal bleeding ${ }^{[21]}$.

The incidence of endometrial hyperplasia varies in different studies from $7 \%$ to $31.4 \%{ }^{[14,15,18]}$ However, the percentage of endometrial hyperplasia obtained in this study $(29.83 \%)$ is in concordance with Patel et al. (29.1\%) ${ }^{[12]}$ and Dass et al $(30.6 \%)^{[14]}$ studies and lowest in the study of Purandhare et al $(7 \%)^{[9]}$.Samal et al reported hyperplastic endometrium was the commonest finding in $32.3 \%$ of DUB cases in postmenopausal women ${ }^{[21]}$. Study of Pilli et al reported the incidence of endometrial hyperplasia to be $44 \%$ high compared to the present study of $29.83 \%$ which partly reflects hyperestrogenic activity ${ }^{[10]}$.

\section{Conclusion}

In this study, Dysfunctional uterine bleeding occurred in both the reproductive and the perimenopausal age groups 
and majorities were multiparous. Menorrhagia was the most common presenting complaint with predominance of proliferative endometrium.

Besides this, it is observed that the age of the patient had a strong bearing on the type and pattern of endometrium seen on histopathological examination. Age has definite influence on endometrial histology.

Histopathological examination of endometrium remains the gold standard method of evaluating the DUB cases and its subtypes and to exclude the local causes which helps in early diagnosis and to determine the plan and mode of management.

\section{References}

1. Algotar KM, Nalawade A. Physiology of menstruation. In: Purandare CN editor: Dysfunctional uterine bleeding -An update. JAYPEE: New Delhi; 2004;1-15.

2. Kumar P, Malhotra N, editors. Abnormal and excessive uterinebleeding. Jeffcoate's Principal of Gynecology. 7th ed. New Delhi: JAYPEE;2008;598-616.

3. Davey DA. Dysfunctional uterine bleeding. In: Whitfield CR editor: Dewhurst's textbook of Obstetrics and Gynecology for postgraduates. 4th ed. London: Blackwell science; $1995 ; 624-45$.

4. Katuwal N,Gurung G,Rana A,Jha A. A clinicopathological study of dysfunctional uterine bleeding.Journal of Pathology of Nepal. 2014;4:635- 38.

5. Munro MG.Abnormal uterine bleeding in the reproductive years. J Am Assoc Gynecol Laparoscop.1999;6:391-428.

6. Ash SJ, Farrell SA, Flowerden G. Endometrial biopsy in DUB. J Reprod Med.1996;41:892-896.

7. Fraser IS.Treatment of ovulatory and anovulatory dysfunctional uterine bleeding with oral progestogens.Aust NZ J Obstet Gynecol.1990;30:353-6

8. Emanuel MH, Verdel MJ, Wamsteker K, Lannes FB.A prospective comparison of transvaginal ultrasonography and diagnostic hysteroscopy in the evaluation of patients with abnormal uterine bleeding.Am J Obstet Gynecol $1995 ; 172: 547-52$.
9. Purandare S, Jhalam L. Pathological picture in Hysterectomy done for abnormal uterine bleeding. J Obstet Gynaecol India. 1993;43:418-21.

10. Pilli GS, Sethi B, Dhaded AV, Mathur PR. Dysfunctional Uterine Bleeding-Study of 100 cases .J Obstet Gynaecol India 2002;52(3):87-9.

11. Shergill SK, Shergill HK, Gupta M, Kaur S. Clinicopathological Study of Hysterectomies. JIMA. 2002;100(4):238-9.

12. Patel SR, Sheth MS, Rawal MY. Dysfunctional Uterine Bleeding- Place of Hysterectomy in its Management. J Postgrad. 1986;32(3):150-3.

13. Sucheta KL,Mallikarjuna M,Madhu KP,Arun BJ,Niranjan N.Hysterectomy:Clinical profile,indications and postoperative complications.Int J Reprod Contracept Obstet Gynecol.2016 Jul;5(7):2093-96.

14. Dass A, Chugh S. Dysfunctional Uterine Bleeding: A clinicpathological study. J Obstet Gynaecol India. 1964;14:34854.

15. Bhattacharji SK. Dysfunctional uterine hemorrhage: correlation of endometrial pattern with clinical behavior. J Obstet Gynaecol India. 1964;14:372-9.

16. Ghosh BK, Sengupta KP. A study of the endometrium and cystohormonal pattern in functional uterine bleeding. J Obstet Gynaeol India.1968;310-6.

17. Mehrotra VG, Mukerjee K, Pandey M, Samanth V. Functional uterine bleeding -A review of 150 cases. J Obstet Gynaecol India. 1972;22:684-9.

18. Joshi SK, Deshapande DH. Clinico - pathological study in 274 cases of dysfunctional uterine hemorrhage. J Obstet Gynaecol India.1964;14:360-71.

19. Muzaffar M, Akhtar K, Yasmin S, Rehman M, Iqbal W, Khan M. Menstrual irregularities with excessive blood loss: a Clinico- Pathological correlation. J Pak Med Assoc 2005;55:1-4.

20. Bhosle A, Fonseca M. Evaluation and histopathological correlation of Abnormal uterine bleeding in Perimenopausal women. Bombay Hospital J 2010;52:69-72.

21. Samal S, Gupta U, Agarwal P, Samal N. Clinico- pathological Study of Dysfunctional Uterine Bleeding in Postmenopausal Women. J Obstet Gynaecol India. 2000;50(6):100-1.

*Corresponding author:

Dr. Ramesh B. H., No.17, 3rd Cross, Triveni Road, KN Extension, Yeshwantpur, Bangalore-22. India

Phone: +91 7411159287

Email: rameshpath@rediffmail.com

Financial or other Competing Interests: None.

Date of Submission : 17.11.2016

Date of Acceptance : 20.04.2017

Date of Publication : 31.08.2017 